JOPAT Vol 19(1), 387 - 397, Jan - June Edition, 2020

ISSN 2636 - 5448, https://doi.org/10.4314/jopat.v19i1.1

\title{
Formulation of non-effervescent floating matrix tablets of metronidazole using Abelmoschus esculentus gum as binder and 2-camphanone as sublimating agent.
}

\author{
Airemwen Collins Ovenseri ${ }^{1 *}$, Uhumwangho Uwumagbe Michael $^{1}$, Obarisiagbon Aiwaguore Johnbull ${ }^{2}$ \\ and Umechukwu Chioma Promise ${ }^{1}$ \\ Department of Pharmaceutics and Pharmaceutical Technology, Faculty of Pharmacy, University of Benin, \\ Nigeria.
}

Department of Pharmaceutics and Pharmaceutical Technology, College of Pharmacy, Igbinedion University, Okada, Edo State.

\begin{abstract}
The aim of this study was to formulate non-effervescent floating drug delivery system of metronidazole tablets using Abelmoschus esculentus (Okra) (AE) gum as a binder and 2-camphanone (camphor ${ }^{\circledR}$ ) as the sublimating agent. Granules were prepared by wet granulation technique using varying concentrations of AE gum $(2,4,6$ and $8 \%$ w/w) admixed with $1 \% \mathrm{w} / \mathrm{w}$ acrylate methacrylate copolymer. A $30 \% \mathrm{w} / \mathrm{w}$ of 2-camphanone was used as the sublimating agent. The granules were characterized for micromeritic properties. And thereafter, compressed at a compression pressure of $25 \mathrm{~N} / \mathrm{m}^{2}$ using a Manesty single punch tableting machine. The metronidazole tablet was then sintered at $70^{\circ} \mathrm{C}$ for $12 \mathrm{~h}$. Drug-excipient compatibility study was done using Fourier Transform Infra-red Spectroscopy (FTIR). Tablets were evaluated for floating lag time, in-vitro buoyancy and release kinetics. FTIR studies showed that the excipients and the active pharmaceutical ingredient (API) i.e. metronidazole, were compatible. All the granules were free flowing, with Carr's index $\leq 15 \%$, Hausner ratio $\leq 1.18$ and angle of repose of $\leq 33.5^{\circ}$. The tablets had hardness and friability values of 5.0-9.5 $\mathrm{N}$ and $0.4-0.8 \%$ respectively. The floating lag time was $0 \mathrm{~s}$ showing that the tablets floated immediately after immersion in the simulated gastric fluid. The maximum $\%$ release $\left(\mathrm{m}_{\infty}\right)$ and time to achieve it $\left(\mathrm{t}_{\infty}\right)$ were $\geq 88 \%$ and $\geq 10 \mathrm{~h}$, respectively. Release exponent $(\mathrm{n})$ for all the formulations had values $>0.45$, hence their release was by non-Fickian diffusion. Non-effervescent floating matrix tablets of metronidazole were formulated using $\mathrm{AE}$ gum as the binder and 2-camphanone as the sublimating agent. The formulated floating tablets had increased in-vitro retention time, which indicated potential for sustained release of the drug. If well developed, this may help reduce the oral dosing frequency and encourage patient adherence to the drug therapy.
\end{abstract}

Keywords: Non-effervescent, Abelmoschus esculentus, 2-camphanone, floating

Name of correspondence: Dr Collins O. Airemwen. Department of Pharmaceutics and Pharmaceutical Technology, Faculty of Pharmacy, University of Benin, P.M.B 1154, Benin-City, Nigeria. Phone no. : +234 8133737933 , Email: collins.airemwen@uniben.edu

(C)2007 The authors. This work is licensed under the Creative Attribution 4.0 International license. 


\section{Journal of Phytomedicine and Therapeutic}

\section{Introduction}

Oral delivery system is the most preferred route of drug administration due to its ease of application, patient adherence and flexibility in formulation [1]. Conventional oral dosage forms provide specific drug concentrations in systemic circulation without offering any control over the delivery [2]. These systems achieve and maintain drug concentrations within therapeutically effective ranges needed for treatment only when taken several times a day. This results in significant fluctuations in drug levels [3]. Floating drug delivery systems (FDDS) are low-density formulations with adequate buoyancy intended to float over gastric contents and remain buoyant in the stomach for prolonged periods without interfering with gastric emptying rate [4]. They have been shown to be of better significance in controlling release rate for drugs having site-specific absorption. Some advantages of FDDS include; controlled drug delivery and reduced frequency of dosing hence, enhanced patient adherence to therapy, increased bioavailability of drugs, It is also suitable for medications with $\mathrm{pH}$ dependent absorption from the stomach e.g. verapamil and furosemide. Targeted delivery of drugs such as anti-ulcer medications, antacids and antibacterial for the management of Helicobacter pylori infection at the stomach and duodenum can be achieved using FDDS. Drugs that are degraded by enzymes in the small and large intestine can also be formulated using FDDS e.g. ranitidine hydrochloride [3]. FDDS have lower bulk densities than the gastric fluid hence, remain afloat in the stomach over a long period of time without interfering with the gastric contents [5].

AE gum is a natural polymer obtained from the pods of okra plant (Abelmoschus esculentus) Family, Malvaceae. It is commonly used as a binder in tablet formulations. The binding and mechanical properties of the gum have been reported by many researchers $[6,7,8]$. However, its use as a binder in the formulation of non-effervescent floating drug delivery system has not been investigated.

Metronidazole is a bitter, slightly saline-tasting drug with a minor odour, which darkens when exposed to light. It is soluble in water, slightly soluble in alcohol and sparingly soluble in chloroform. It is an antiamoebic, anti-protozoal, anti-bacterial, anti-parasitic and anti-trichomonal agent [4].

Camphor $^{\circledR}$ is a waxy, flammable, transparent solid with a strong aroma. It is a terpenoid with the chemical formular $\mathrm{C}_{10} \mathrm{H}_{16} \mathrm{O}$. It is found in the wood of camphor laurel (Cinnamomum camphora), a large evergreen tree found in Asia and can also be synthesized from the oil of turpentine. It is used for its scent, as an ingredient in cooking, embalming fluid and sublimating agent for medicinal purposes and in religious ceremonies [9]. Sublimating agents are substances that transform from the solid state to the gaseous state without becoming a liquid. Examples of sublimating agents include iodine, ammonium carbonate and camphor ${ }^{\circledR}$. The role of the sublimating agent in the formulation is to sublime into gas and evaporate from the solid dosage form when placed in an oven at controlled temperature. The pores generated in the tablets reduce the bulk density of the tablets and enable them to float when immersed in the dissolution medium.

The aim of this study was to formulate a noneffervescent floating drug delivery system of metronidazole using $\mathrm{AE}$ as a binder and 2camphanone as the sublimating agent. Noneffervescent technique offers no floating lag time as compared to the effervescent method with prolonged floating lag time and sometimes fails to float on top of the simulated gastric fluid [10]. 


\section{Journal of Phytomedicine and Therapeutic}

Materials and Methods

\section{Materials}

The active ingredient used in the study as drug model was metronidazole (Ranbaxy, India), acrylate methacrylate copolymer was obtained from Rhoma Pharma, Darmstadt, Germany, AE gum was extracted by method previously described with slight modification [8], camphor (Cipla Ltd, India) was used as the sublimating agent. All other chemicals were of analytical grades.

\section{Methods}

\section{Granulation and micromeritic properties of the granules}

Floating metronidazole granules were formulated by wet granulation technique. Four batches were prepared using $\mathrm{AE}$ gum at varying concentrations (2.0, 4.0, 6.0 and $8.0 \% \mathrm{w} / \mathrm{w}$ ) with $1.0 \% \mathrm{w} / \mathrm{w}$ of Eudragit ${ }^{\circledR}$ RL100. One extra batch was also prepared without the addition of Eudragit ${ }^{\circledR}$ RL100 at $2 \%$ w/w concentration. In each formulation, lactose and metronidazole were mixed in the dry state in a mortar using the geometric mixing method. Then aqueous dispersion of the binder mixtures of the gum and Eudragit ${ }^{\circledR}$ RL100 were used to wet mass the powder in the mortar. The damp mass formed was forced through a sieve of mesh size 850.0 $\mu \mathrm{m}$ and dried at $60{ }^{\circ} \mathrm{C}$ for $15 \mathrm{~min}$ in an oven. It was then sieved using a sieve mesh of $710.0 \mu \mathrm{m}$. 2camphanone and talc were then incorporated into the granules extragranularly, prior to compression.

The packing properties of the granules were determined by measuring the bulk density (BD) and tapped density (TD) using standard procedures [8], and values were obtained using equations 1 and 2, respectively. From the data obtained, Carr's Index (CI) values of the granules were determined using equation 3 . The flow properties were obtained by measuring the angle of repose formed when a sample of the granules $(20.0 \mathrm{~g})$ was allowed to flow freely through the stem of a funnel onto a horizontal bench surface. The angle of repose was determined using equation 4.

$$
\text { Bulk density }\left(\mathrm{g} / \mathrm{cm}^{3}\right)=\frac{\text { mass of granules }}{\text { initial volume of granules }}-
$$

Tap density $\left(\mathrm{g} / \mathrm{cm}^{3}\right)=$

$$
\frac{\text { mass of granules }}{\text { tapped volume of granules }}-
$$

Carr Index $=\frac{\text { Tapped density }- \text { Bulk density }}{\text { Tapped density }}-$

Angle of repose

$$
(\theta)=\operatorname{Tan}^{-1} h / r \quad \quad-\quad-
$$

Where $=\theta$ is the angle of repose, $\mathrm{h}=$ height and $\mathrm{r}=$ the radius of the heap formed in $\mathrm{cm}$.

\section{Formulation of the tablets}

The composition of metronidazole floating tablet formulae is shown in Table 1. A Manesty Single Punch Tableting Machine (Type F3 Manesty Machines, UK) was used to compress the granules into tablets. The granules supposedly containing $400.0 \mathrm{mg}$ of metronidazole were placed in the die and compressed at a pressure of $25 \mathrm{~N} / \mathrm{m}^{2}$. This pressure was maintained constant for all the batches of floating tablets produced. The resulting tablets were collected, dusted and stored in an air tight jar containing activated silica gel as a desiccant and then the formulated tablets were then sintered (heated) in a hot air oven at $70^{\circ} \mathrm{C}$ for $12 \mathrm{~h}$. 


\section{Journal of Phytomedicine and Therapeutic}

Table 1: The formulae of the metronidazole floating tablet.

\begin{tabular}{lll}
\hline S/N & Ingredients & Quantity \\
\hline 1 & Metronidazole powder & $400 \mathrm{mg}$ \\
2 & AE gum & $2,4,6,8 \% \mathrm{w} / \mathrm{w}$ \\
3 & Camphor & $30 \%$ \\
4 & Talc powder & $1 \%$ \\
5 & Acrylate methacrylate copolymer & $1 \%$ \\
\hline
\end{tabular}

\section{Evaluation of the formulated tablets}

\section{Hardness and friability}

The tablet hardness was determined by diametrical compression using the Campbell electronics hardness tester (HT-30/50, India). The pressure required to fracture a tablet placed in the anvil of the hardness tester was determined. Five (5) tablets were used for the test. The mean value and standard deviation were recorded. Ten (10) tablets were randomly selected for the friability test using the Roche friabilator (Erweka, Germany). The initial weight of the tablets was obtained before they were placed in the friabilator which was allowed to operate at $25 \mathrm{rpm}$ for $4 \mathrm{~min}$ after which the final weight of the tablets was determined. These values were used to calculate the percentage friability (\%) using equation 5 .

Friability $=\frac{\text { Initial weight-Final weight }}{\text { Initial } \text { weight }} \times 100-\quad-5$

\section{Floating lag time (FLT) and in vitro buoyancy test}

The method described previously by Rosa et al., [11] was adopted. A $1000 \mathrm{~mL}$ beaker was filled with 900.0 $\mathrm{mL}$ simulated gastric fluid $(0.1 \mathrm{~N} \mathrm{HCl})$. A tablet was immersed in the medium which was kept stagnant and maintained at $37 \pm 2{ }^{\circ} \mathrm{C}$. The time taken for the tablet to rise to the surface and float was obtained as the FLT. The time duration for which the tablet floated and remained afloat without fracturing was taken as the in vitro buoyancy time.

\section{In vitro dissolution studies and drug release kinetics}

The rotating basket method was used and dissolution studies were performed using $900.0 \mathrm{~mL}$ of $0.1 \mathrm{~N} \mathrm{HCl}$ maintained at $37 \pm 2^{\circ} \mathrm{C}$ as the medium. One tablet was placed in a cylindrical basket, immersed in the dissolution medium which was agitated at $100 \mathrm{rpm}$ using a single blade GallenKamp stirrer (Model APP No 4B 5784A). At predetermined time intervals (5, 10, 15 and $30 \mathrm{~min}, 1,2,3,4,5,6,7,8,9$ and $10 \mathrm{~h}$ ), $5.0 \mathrm{~mL}$ samples were withdrawn using a pipette fitted with a cotton wool plug. Equal amounts of fresh dissolution medium kept at the same temperature was used to replace the withdrawn fluid. The withdrawn samples were filtered again after using the plug of cotton wool, diluted and their absorbance determined with a UV/Visible spectrophotometer (Model Spectronic 21D, Bausch and Lomvb, USA) at a maximum wavelength $\left(\lambda_{\max }\right)$ of $277 \mathrm{~nm}$. The determination was done in triplicates and the mean results reported. The corresponding amount of metronidazole released at any time $\mathrm{t}$, was determined.

The data obtained from the dissolution studies were subjected to various mathematical models such as zero order, first order and Higuchi square root of time relationship $[12,13,14]$ to evaluate the drug release kinetics. The mechanism of drug release from the 


\section{Journal of Phytomedicine and Therapeutic}

formulation was determined using KorsemeyerPeppas model. The linear regression coefficient $\left(r^{2}\right)$ for each rate order was computed. The model that best fits the release data is selected based on correlation coefficient value [14].

\section{Compatibility studies}

Compatibility studies were carried out using Fourier Transform Infra-Red (FTIR) spectrophotometer and the spectra of the pure drug; admixture of metronidazole, AE gum plus other ingredients; and the tablet formulation containing $8 \%$ w/w AE gum were studied.

\section{Statistical analysis}

The data obtained were recorded as mean \pm standard deviation (SD). All the data were subjected to statistical analysis using Student $t$ - test to test for significance of difference. $\mathrm{P}<0.05$ was considered to be significant.

\section{Results and discussion}

\section{Micromeritic properties of the granules}

The results of the micromeritic properties of the FMG formulated using varying concentrations of $\mathrm{AE}$ gum are shown in Table 2. It was observed that all the granules produced with $\mathrm{AE}$ gum had angle of repose ranging from 28.6 - $33.5^{\circ}$ while Carr's index values ranged from 10.3 - $15.0 \%$. The Hausner ratio was between 1.11 - 1.18. The results of the micromeritic properties revealed that all the granules exhibited good flow which is very vital in ensuring weight and content uniformities during tableting.

Table 2: Micromeritic properties of metronidazole floating matrix granules prepared using AE gum as binder.

\begin{tabular}{lllllc}
\hline AE & $\begin{array}{l}\text { Bulk Density } \\
\left(\mathbf{g} / \mathbf{c m}^{\mathbf{3}}\right)\end{array}$ & $\begin{array}{l}\text { Tap Density } \\
\left(\mathbf{g} / \mathbf{c m}^{\mathbf{3}}\right)\end{array}$ & $\begin{array}{l}\text { Angle of repose } \\
(\mathbf{o})\end{array}$ & $\begin{array}{l}\text { Carr's } \\
(\%)\end{array}$ & $\begin{array}{c}\text { index } \\
\text { Rausner's }\end{array}$ \\
\hline AE1 & $0.52 \pm 0.03$ & $0.58 \pm 0.02$ & $28.6 \pm 1.0$ & $10.3 \pm 1.0$ & $1.12 \pm 0.01$ \\
AE2 & $0.58 \pm 0.02$ & $0.66 \pm 0.03$ & $30.0 \pm 1.1$ & $12.1 \pm 1.2$ & $1.14 \pm 0.01$ \\
AE3 & $0.54 \pm 0.03$ & $0.61 \pm 0.01$ & $32.3 \pm 1.0$ & $11.5 \pm 1.3$ & $1.13 \pm 0.02$ \\
AE4 & $0.53 \pm 0.01$ & $0.61 \pm 0.03$ & $31.0 \pm 1.1$ & $13.1 \pm 1.2$ & $1.15 \pm 0.01$ \\
AE5 & $0.51 \pm 0.02$ & $0.60 \pm 0.02$ & $33.5 \pm 1.2$ & $15.0 \pm 1.0$ & $1.18 \pm 0.02$
\end{tabular}

where; AE1 (AEG alone), AE2 (2:1), AE3 (4:1), AE4 (6:1), AE5 (8:1)

AE1-2\% w/w AE gum alone, AE2- 2\%w/w AE gum admixed with 1\% w/w Eudragit, AE3-4\%w/w AE gum admixed with $1 \%$ w/w Eudragit, AE4- 6\%w/w AE gum admixed with 1\% w/w Eudragit, AE2- 8\%w/w AE gum admixed with $1 \% \mathrm{w} / \mathrm{w}$ Eudragit.

Post compression parameters of the formulated tablets

\section{Tablet hardness, friability and drug content}

The results of the hardness, friability and drug content tests are shown in Table 3. The hardness of the formulated tablets in the various formulations
(AE1-AE5) varied from $5.0 \pm 1.1$ to $9.5 \pm 1.1 \mathrm{~N}$ indicating good mechanical strength with an ability to withstand physical and mechanical stress during packaging, handling, storage and transportation. The loss in total weight of the tablets due to friability was in the range of $0.4 \pm 0.2$ to $0.8 \pm 0.1 \%$ in all the formulations and the values were less than $1 \%$ which 


\section{Journal of Phytomedicine and Therapeutic}

indicates that the formulated tablets were

mechanically stable to withstand fracture and abrasion due to handling, packaging, transportation and storage. The drug content of the different tablet formulations was uniform and $\leq 86 \%$ which is within the permissible limits of the British Pharmacopoeia [15].

Table 3: Results of hardness, friability and drug content of metronidazole floating matrix tablets

AE

AE1

AE2

AE3

AE4

AE5

\section{Hardness (N)}

Friability (\%)

\section{Drug Content}

$\begin{array}{lll}5.0 \pm 1.1 & 0.4 \pm 0.2 & 96 \\ 6.3 \pm 1.0 & 0.5 \pm 0.1 & 94 \\ 6.9 \pm 1.2 & 0.5 \pm 0.1 & 90 \\ 7.8 \pm 1.0 & 0.7 \pm 0.2 & 88 \\ 9.5 \pm 1.1 & 0.8 \pm 0.1 & 86\end{array}$

Floating lag time and in vitro buoyancy of floating matrix tablets

The results of the in vitro buoyancy study are presented in Table 4. The results showed that all the tablet formulations had no floating lag time (0 s) as they floated instantaneously when placed on the simulated gastric fluid $(0.1 \mathrm{~N} \mathrm{HCl})$. The mechanism of floating was due to the sublimation of the 2camphanone from the tablets during the sintering (heating) process thereby creating pores in the tablets which enabled the tablets to float freely on top of the simulated gastric fluid. The sublimation of the 2camphanone from the dosage form also reduced the bulk density of the tablets less than that of the simulated gastric fluid thus aiding the buoyancy of the tablets $[4,10]$.
Batch AE1 (2 \%w/w AE gum without acrylate methacrylate copolymer) showed buoyancy duration without rupture of $20 \mathrm{~min}$ while the other batches had $>10 \mathrm{~h}$. However, the floating time of the AE1 tablets was quite short due to erosion caused by the penetration of the dissolution medium into the uncoated porous tablet core resulting in drowning [5]. This indicated that acrylate methacrylate copolymer helped to maintain the integrity of the tablets thereby improving the buoyancy time hence making the tablets to remain afloat over a long period of time. Therefore, the addition of acrylate methacrylate copolymer helped to increase the integrity and improved the buoyancy time of the tablet formulations of batches AE2-AE5 [4]. The diagram of the in-vitro buoyancy characteristics of the floating matrix tablets formulated with AE gum is presented in Figure 1. 


\section{Journal of Phytomedicine and Therapeutic}

Table 4: Floating lag time and in-vitro buoyancy studies of the metronidazole floating matrix tablet.
AE gum
$\mathrm{AE}$
AE2 AE3
AE4 AE5

\begin{tabular}{llllll}
\hline Floating lag time (s) & 0 & 0 & 0 & 0 & 0 \\
Buoyancy time without rupture of & 0.3 & 6 & 8 & 10 & 12 \\
Tablet (h) & & & & &
\end{tabular}

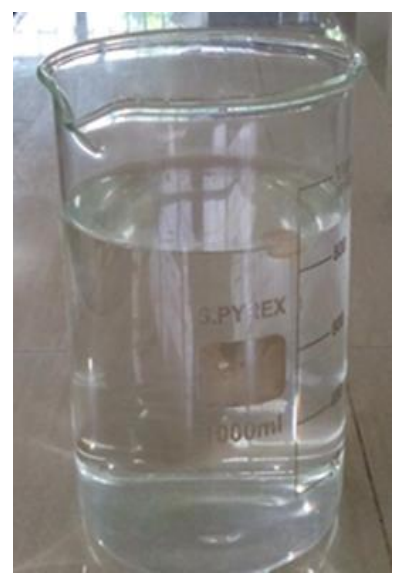

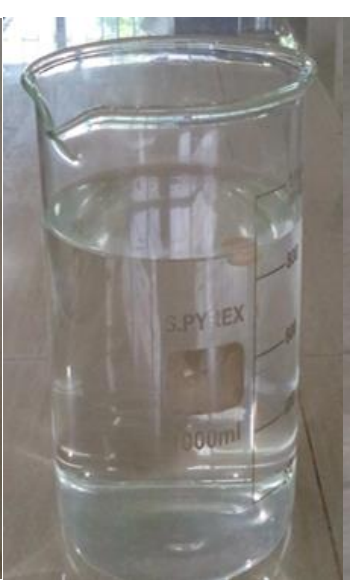

b

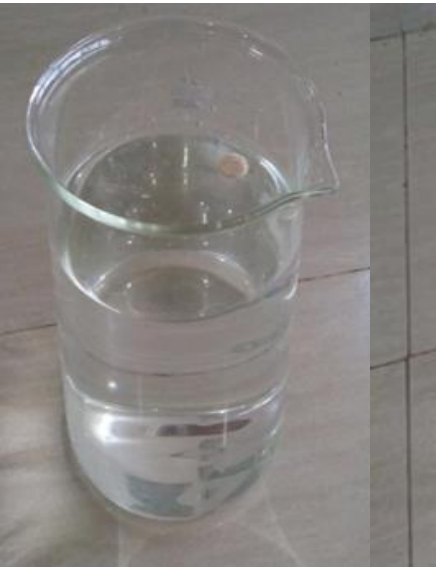

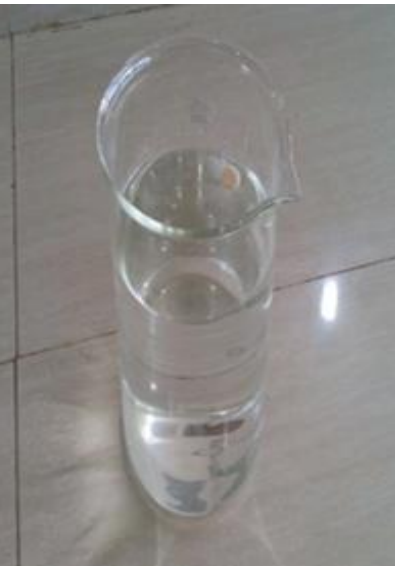

d

Figure 1: Photographs showing the in-vitro buoyancy characteristics of metronidazole floating tablets formulated with varying concentrations of Albemoschus esculentus gum

(a) Photograph taken immediately after placing the tablet into the beaker;

(b),

(c) and (d) Photographs taken after 2, 4 and $6 \mathrm{~h}$ of immersing the tablet in the simulated gastric fluid.

\section{Release profile of floating matrix tablets of} metronidazole

The in-vitro drug release profiles of the floating matrix tablets of metronidazole formulated using $\mathrm{AE}$ gum are shown in Figure 2. The drug release from the tablets formulated using $2 \% \mathrm{w} / \mathrm{w}$ AE gum without acrylate methacrylate copolymer (batch AE1) showed faster release compared to the other batches (AE2AE5). This might be due to the fact that the copolymer helped in maintaining the integrity of the tablet and retarded the drug release from the tablet formulations. It was also observed that there was a decrease in the rate of release of the drug as the concentration of the gum increased. Batch AE1 released about $98 \%$ of its drug content within $2 \mathrm{~h}$ while batches AE2 - AE5 achieved 75 - $95 \%$ release in $8 \mathrm{~h}$. Thus, there was a more sustained release of drug particles from batches AE2 - AE5. This shows that the release profile of the tablet was dependent on gum concentration. The higher the concentration of the gum, the more sustained the release of the drug from the matrix of the tablet [5]. This may be due to 


\section{Journal of Phytomedicine and Therapeutic}

low permeability which acts as a rate-controlling factor in retarding drug release from matrix systems.

It was also observed that the time to attain maximum release in the floating tablets decreased as the concentration of the gum increased. The drug release from the matrix tablet resulted from slow diffusion of dissolved drug molecules through aqueous-filled channels in the polymeric network. The dissolution parameters are presented in Table 5. The maximum drug released $\left(\mathrm{m}_{\infty}\right)$, the time to achieve that $\left(\mathrm{t}_{\infty}\right)$ and the dissolution rate $\left(\mathrm{m}_{\infty} / \mathrm{t}_{\infty}\right)$ for batch $\mathrm{AE} 1$ were 98 $\%, 2 \mathrm{~h}$ and $49 \% \mathrm{~h}^{-1}$, respectively while the corresponding values for AE5 were $88 \%, 10 \mathrm{~h}$ and $8.8 \% \mathrm{~h}^{-1}$.

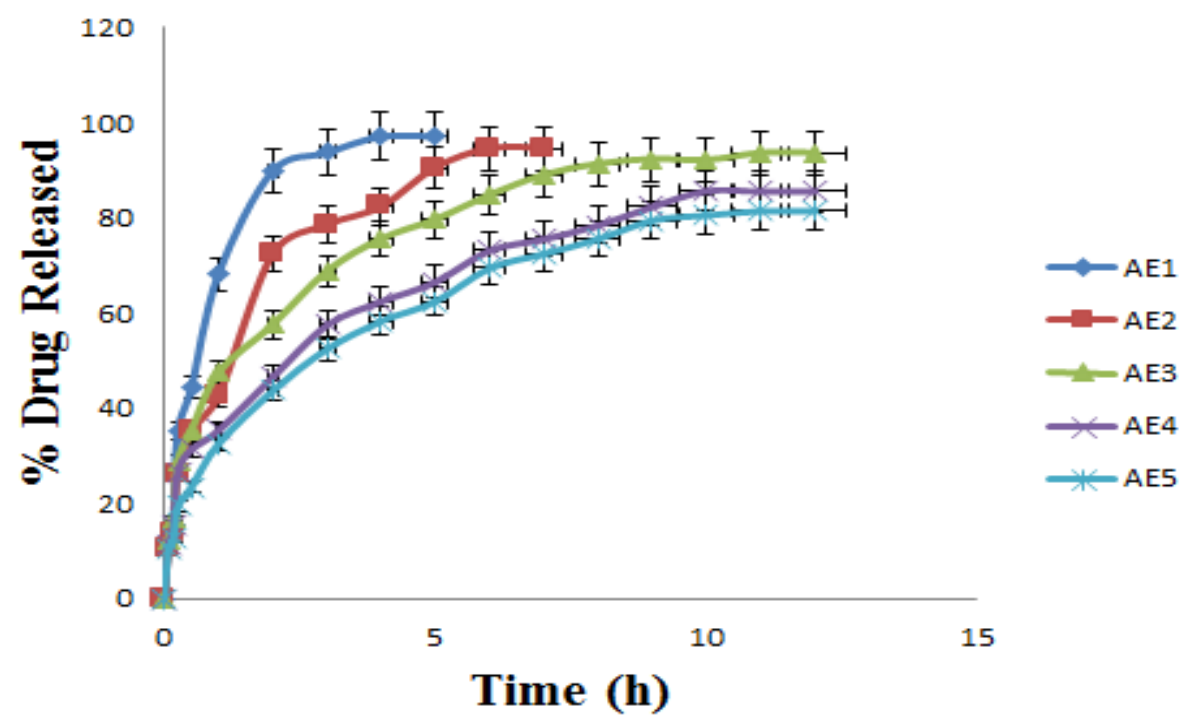

Figure 2: Drug release profiles of metronidazole floating matrix tablets prepared with varying concentrations of AE, where AE1 (AE alone), AE2 (2:1), AE3 (4:1), AE4 (6:1), AE5 (8:1).

Table 5: Dissolution parameters of floating metronidazole tablets formulated with $\mathbf{A E}$ gum $\mathbf{m}_{\infty}(\%)$, $\mathbf{t}_{\infty}(\mathbf{h})$, $\mathbf{m}_{\infty} / \mathbf{t}_{\infty}\left(\% \mathbf{h}^{-1}\right)$

\begin{tabular}{llll}
\hline AE: & $\mathbf{m}_{\infty}(\boldsymbol{\%})$ & $\mathbf{t}_{\infty}(\mathbf{h})$ & $\left(\mathbf{m}_{\infty} / \mathbf{t}_{\infty} \mathbf{h}^{\mathbf{- 1}}\right)$ \\
\hline AE1 & & & \\
AE2 & 98.0 & 2 & 49.0 \\
AE3 & 94.2 & 4 & 15.7 \\
AE4 & 92.0 & 6 & 15.3 \\
AE5 & 90.6 & 10 & 9.1 \\
\hline
\end{tabular}




\section{Journal of Phytomedicine and Therapeutic}

Release kinetics and mechanism of drug release from the floating matrix tablets

The results of the various release kinetics for the floating metronidazole tablets are presented in Table 6. The release kinetics did not follow zero order release pattern as the plot showed poor linearity with regression values ranging from $0.769-0.869$. In the zero order, the amount of drug released is expected to be constant irrespective of the concentration of the drug left in the dosage form. Although the desired release model for controlled drug delivery system is zero order, this was not attained in this study.

When the data obtained were plotted according to the first order equation, it showed a fair linearity with regression values $\left(\mathrm{r}^{2}\right)$ ranging from $0.958-0.981$. This implied that the amount of drug released was dependent on the amount of drug left in the formulation. The in-vitro release profiles of the floating metronidazole tablets were best expressed by Higuchi's equation as the plots showed high linearity with $\mathrm{r}^{2}$ values in the range of 0.925-0.982. The release kinetics were more consistent with this model since there were higher correlations when compared to other models analyzed. This showed that the release from the matrix tablet were mainly by Higuchi model which states that the amount of drug released is dependent on the square root of time [12].

Fitting of the data obtained into Korsemeyer-Peppas equation showed poor linearity with $r^{2}$ values in the range of 0.221-0.471. Since the $r^{2}$ values were consistent with Higuchi's model, it was expected that the mechanism of drug release from the matrix tablet was diffusion controlled. The release exponent (n) for the floating metronidazole tablets ranged from 0.470.53. The formulations AE1 to AE5 had their release exponents $(n)>0.45$; hence the release mechanism was by non-Fickian diffusion. This implied that diffusion was the dominant mechanism of drug release.

Table 6: Correlation coefficient and release kinetics of metronidazole floating tablets $(n=3)$ prepared with varying concentrations of $\mathrm{AE}$ gum.

\begin{tabular}{|c|c|c|c|c|c|c|c|c|}
\hline Models & Zero & & First & & Higuchi & & Korse & r-Peppas \\
\hline Formulations & $\mathbf{r}^{2}$ & $\mathbf{K}_{\mathbf{0}}$ & $\mathbf{r}^{2}$ & $K_{1}$ & $\mathbf{r}^{2}$ & $\mathbf{K}_{\mathbf{H}}$ & $\mathbf{r}^{2}$ & $\mathbf{N}$ \\
\hline AE1 & 0.769 & 18.59 & 0.958 & -0.34 & 0.925 & 47.76 & 0.221 & 0.48 \\
\hline AE2 & 0.842 & 12.98 & 0.981 & -0.19 & 0.964 & 38.18 & 0.346 & 0.53 \\
\hline AE3 & 0.791 & 6.86 & 0.963 & -0.10 & 0.944 & 26.96 & 0.406 & 0.47 \\
\hline AE4 & 0.854 & 6.35 & 0.972 & -0.07 & 0.973 & 24.37 & 0.416 & 0.46 \\
\hline AE5 & 0.869 & 6.31 & 0.967 & -0.06 & 0.982 & 24.12 & 0.471 & 0.49 \\
\hline
\end{tabular}




\section{Journal of Phytomedicine and Therapeutic}

\section{Compatibility studies}

The results of the compatibility studies are presented in Figure 3. It was observed that there were no obvious changes in peaks due to the presence of other excipients and also due to compression to final tablets. This indicates that the API (metronidazole) and the other excipients were compatible.

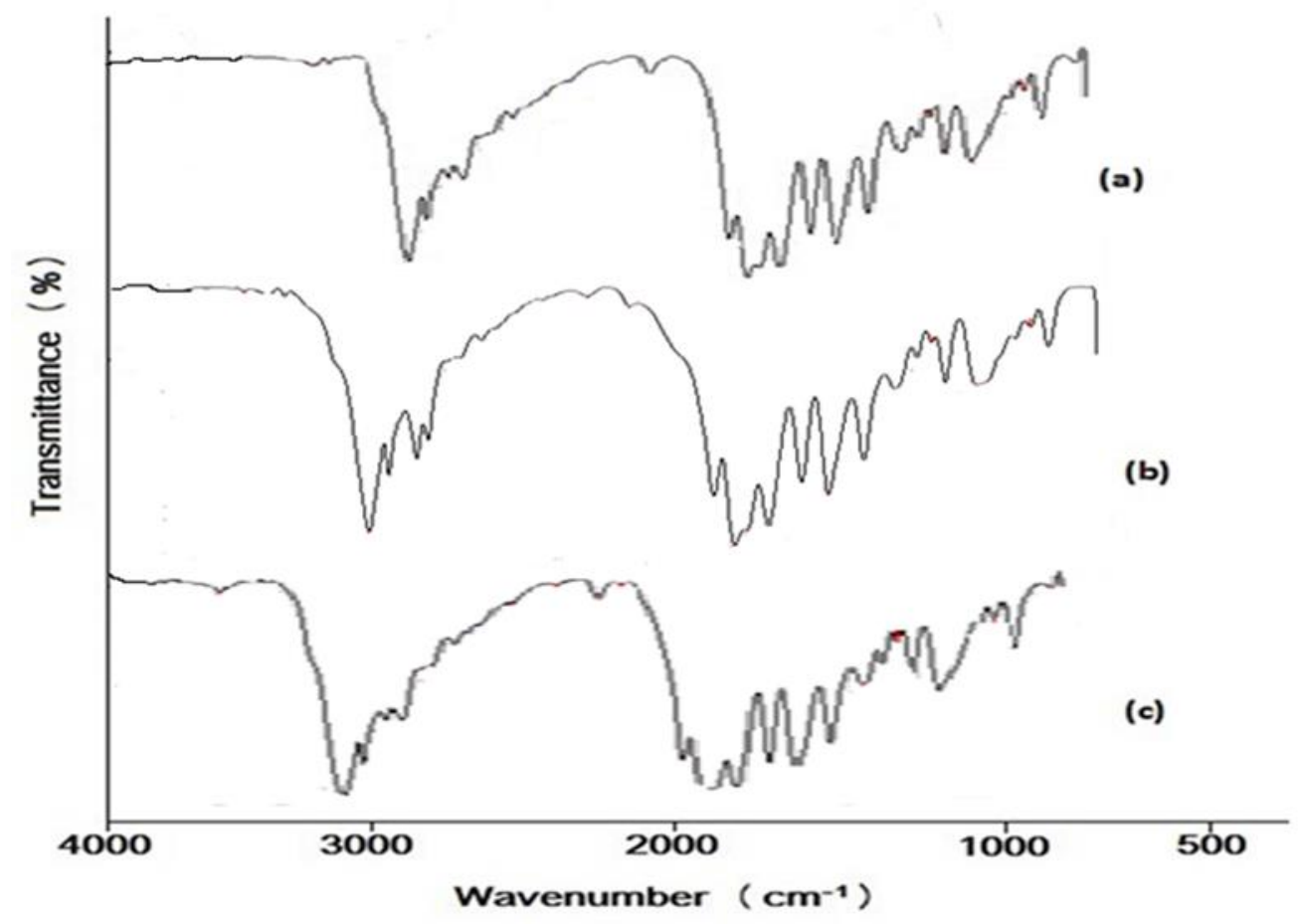

Figure 3: FTIR Spectra of a) pure metronidazole sample (b) $8 \% \mathrm{w} / \mathrm{w}$ tablet formulation. (c) physical mixture of metronidazole, AE gum and talc.

\section{Conclusion}

Non-effervescent gastro-floating matrix tablets of metronidazole were formulated using $\mathrm{AE}$ gum as the binder and 2-camphonone as the sublimating agent. The formulated dosage form increased the retention time and sustained the release of the drug from the dosage form thereby reducing the frequency of dosing as well as improving patient adherence to therapy.

\section{References}

1. Shivakumar HG, Gowda DV and Pramodkumar TM (2004). Floating controlled drug delivery systems for prolonged gastric residence:A Review. Indian J Pharm Edu; 38 (4):172-180. 


\section{Journal of Phytomedicine and Therapeutic}

2. Chawla G, Gupta P, Koradia V and Bansal AK (2003). Gastroretention: A means to address regional variability in intestinal drug absorption. Pharm Tech; 27 (7):50-68.

3. Airemwen $\mathrm{CO}$ and Uhumwangho $\mathrm{MU}$ (2017). Gastro-floating Drug Delivery System-A Review. Trop J Nat Prod Res. 1(3):105-109.

4. Airemwen $\mathrm{CO}$ and Uhumwangho $\mathrm{MU}$ (2018). Formulation and Evaluation of Gastroretentive Floating Matrix Tablets of Metronidazole using a Novel Noneffervescent Technique, Saudi J. Med. Pharm. Sci; 4 (2): 257-264.

5. Huanbutta $\mathrm{K}$, Limmatvapirat $\mathrm{S}$ and Sungthongjeen S (2016). AAPS Pharmarmaceutical Science Technology, 17 (2): 693-698.

6. Nep EI, Patricia OO, Ndidi CN and Patrick OO (2013). Pharmaceutical properties and application of a natural polymer from Abelmoschus esculentus. Nigeria J Poly Sci and Tech 4(8) 151-156.

7. Okoye EI, Onyekweli AO, and Kunle OO (2011). "Okra gum — an economic choice for the amelioration of capping and lamination in tablets," Annals of Bio Res, 2 (2), 30-42.

8. Nurul DZ, Mohamed IN and ALI K (2014). The Use of Hibiscus esculentus (Okra) Gum in Sustaining the Release of Propranolol
Hydrochloride in a Solid Oral Dosage Form, Biomed Res Int, 3 (5) 165-172.

9. Mann JC, Hobbs JB, Banthorpe DV and Harborne JB (1994). Natural products: their chemistry and biological significance. Harlow, Essex, England: Longman Scientific and Technical pp. 309-311, ISBN 978-0-582-06009-8.

10. Airemwen $\mathrm{CO}$ and Uhumwangho $\mathrm{MU}$ (2019). A Comparative Study Of Floating Drug Delivery System Of Metronidazole Formulated Using Effervescent And Noneffervescent Techniques, J Pharm and Allied Sci 16 (3) 2028 - 3043.

11. Rosa M, Zia H and Rhodes T (1994). Dosing and testing in vitro of a bioadhesive and floating drug delivery system for oral application. Int J Pharm. 105: 65-70.

12. Higuchi T (1963). Mechanism of sustained action medication. Theoretical analysis of rate release of solid drugs dispersed in solid matrices. J Pharma Sci: 52: 1145-1149.

13. Korsemeyer RW, Gurny R, Doelker EM, Buri P and Peppas NA (1983). Mechanism of solute release from porous hydrophilic polymers. Int J Pharm: 15: 25-35.

14. Peppas NA (1985). Analysis of Fickian and nonFickian drug release from polymers. Pharm Acta Helv. 60:110-111.

15. British Pharmacopoeia (2002). London, UK: Her Majesty’s Stationery Office: A234. 